\title{
A multicenter analysis of the clinical microbiology and antimicrobial usage in hospitalized patients in the US with or without COVID-19
}

Laura Puzniak ${ }^{1 *}$, Lyn Finelli ${ }^{1}$, Kalvin C. Yu², Karri A. Bauer ${ }^{1}$, Pamela Moise ${ }^{1}$, Carisa De Anda ${ }^{1}$, Latha Vankeepuram², Aryana Sepassi ${ }^{2}$ and Vikas Gupta²

\begin{abstract}
Background: Past respiratory viral epidemics suggest that bacterial infections impact clinical outcomes. There is minimal information on potential co-pathogens in patients with coronavirus disease-2019 (COVID-19) in the US. We analyzed pathogens, antimicrobial use, and healthcare utilization in hospitalized US patients with and without severe acute respiratory syndrome-coronavirus-2 (SARS-CoV-2).

Methods: This multicenter retrospective study included patients with $>1$ day of inpatient admission and discharge/ death between March 1 and May 31, 2020 at 241 US acute care hospitals in the BD Insights Research Database. We assessed microbiological testing data, antimicrobial utilization in admitted patients with $\geq 24 \mathrm{~h}$ of antimicrobial therapy, and length of stay (LOS).

Results: A total of 141,621 patients were tested for SARS-CoV-2 (17,003 [12.0\%] positive) and 449,339 patients were not tested. Most (>90\%) patients tested for SARS-CoV-2 had additional microbiologic testing performed compared with $41.9 \%$ of SARS-CoV-2-untested patients. Non-SARS-CoV-2 pathogen rates were 20.9\% for SARS-CoV-2-positive patients compared with 21.3 and $27.9 \%$ for SARS-CoV-2-negative and -untested patients, respectively. Gramnegative bacteria were the most common pathogens $(45.5,44.1$, and $43.5 \%$ for SARS-CoV-2-positive, -negative, and -untested patients). SARS-CoV-2-positive patients had higher rates of hospital-onset (versus admission-onset) nonSARS-CoV-2 pathogens compared with SARS-CoV-2-negative or -untested patients (42.4, 22.2, and 19.5\%, respectively), more antimicrobial usage (68.0, 45.2 , and $25.1 \%$ of patients), and longer hospital LOS (mean [standard deviation (SD)] of 8.6 [11.4], 5.1 [8.9], and 4.2 [8.0] days) and intensive care unit (ICU) LOS (mean [SD] of 7.8 [8.5], 3.6 [6.2], and 3.6 [5.9] days). For all groups, the presence of a non-SARS-CoV-2 pathogen was associated with increased hospital LOS (mean [SD] days for patients with versus without a non-SARS-CoV-2 pathogen: 13.7 [15.7] vs 7.3 [9.6] days for SARS-CoV-2-positive patients, 8.2 [11.5] vs 4.3 [7.9] days for SARS-CoV-2-negative patients, and 7.1 [11.0] vs 3.9 [7.4] days for SARS-CoV-2-untested patients).
\end{abstract}

(Continued on next page)

\footnotetext{
* Correspondence: Laura.Puzniak@merck.com

${ }^{1}$ Merck \& Co., Inc., Kenilworth, NJ, USA

Full list of author information is available at the end of the article
}

(c) The Author(s). 2021 Open Access This article is licensed under a Creative Commons Attribution 4.0 International License, which permits use, sharing, adaptation, distribution and reproduction in any medium or format, as long as you give appropriate credit to the original author(s) and the source, provide a link to the Creative Commons licence, and indicate if changes were made. The images or other third party material in this article are included in the article's Creative Commons licence, unless indicated otherwise in a credit line to the material. If material is not included in the article's Creative Commons licence and your intended use is not permitted by statutory regulation or exceeds the permitted use, you will need to obtain permission directly from the copyright holder. To view a copy of this licence, visit http://creativecommons.org/licenses/by/4.0/ The Creative Commons Public Domain Dedication waiver (http://creativecommons.org/publicdomain/zero/1.0/) applies to the data made available in this article, unless otherwise stated in a credit line to the data. 
(Continued from previous page)

Conclusions: Despite similar rates of non-SARS-CoV-2 pathogens in SARS-CoV-2-positive, -negative, and -untested patients, SARS-CoV-2 was associated with higher rates of hospital-onset infections, greater antimicrobial usage, and extended hospital and ICU LOS. This finding highlights the heavy burden of the COVID-19 pandemic on healthcare systems and suggests possible opportunities for diagnostic and antimicrobial stewardship.

Keywords: SARS-CoV-2, COVID-19, Epidemiology, Antibiotics, Pathogens, Coinfection

\section{Background}

Coronavirus disease 2019 (COVID-19), which is caused by severe acute respiratory syndrome coronavirus 2 (SARS-CoV-2), emerged in Wuhan, China in December of 2019 and became a pandemic. Past respiratory virus epidemics suggest an increased risk for bacterial, fungal, or other viral coinfections or superinfections due to biological factors, underlying conditions, and healthcare exposures [1, 2]. Varying coinfection and superinfection rates have been reported in patients with COVID-19, ranging from 5 to $33 \%$ depending on methods, populations, and geographic location (reviewed by Clancy and Nguyen [3] and Rawson et al. [4]). Overall, there is currently limited and often divergent information available on the frequency and microbiology of coinfections and superinfections in patients with COVID-19 [5]. Differences in the methods used for testing criteria, obtaining samples (particularly for nasopharyngeal sources), and storing specimens complicates data comparison and interpretation.

There are also limited data on antimicrobial usage in COVID-19 patients; available studies suggest that the use of broad-spectrum antibiotics is widespread in this population [4]. Such treatment patterns have potential implications for development of antibiotic resistance in both hospital and community settings [6], increased risk for other infections, such as Clostridium difficile, and potential adverse events and toxicity. More complete data on pathogen rates and antimicrobial usage are needed to support appropriate clinical management and antimicrobial stewardship policies during the pandemic $[3,4]$.

In this study, we used data from a large US hospital database to analyze and compare pathogen rates, antimicrobial utilization patterns, and health outcomes among SARS-CoV-2-positive, SARS-CoV-2-negative, and SARS-CoV-2-untested hospitalized adult patients.

\section{Methods}

\section{Study design}

We conducted a multi-center, retrospective cohort analysis of data from 241 US medical facilities. Reporting institutions were part of the BD Insights Research Database (Becton, Dickinson and Company, Franklin Lakes, NJ), which includes both small and large hospitals and medical care facilities in urban and rural areas throughout the US (BD Insights Research Database [Becton, Dickinson \& Company, Franklin Lakes, NJ]) [7-9]. More information on these facilities can be found in the Results section and in Supplementary Table 1 (see Additional file 1). Eligible admissions were hospitalized patients with >1-day inpatient admission and a record of discharge or death between March 1, 2020 and May 31, 2020. For purposes of comparison, patients were classified into 3 groups: (1) tested and positive for SARS-CoV-2; (2) tested and negative for SARS-CoV-2; and (3) not tested for SARS-CoV-2 (referred to as "untested").

All microbiology results were based on local testing performed by individual microbiology labs in the cohort of hospitals in the BD Insights Research Database. SARS-CoV-2 status was determined by in-hospital or ambulatory PCR or antigen assays performed within 7 days of or during admission. For the purpose of this study, a pathogen was defined as a microorganism with the potential to cause disease; the association of the microorganism with a clinically relevant infection was not assessed. Microorganism identification was based on various tests, including conventional cultures, molecular tests, urine antigen tests, and blood serology, as performed by individual local laboratories. Aspergillus identification was based on culture data; galactomannan immunoassays were not included. Pathogens were identified from blood, respiratory tract (upper/lower), urine, intra-abdominal, skin/wound, and other sources and classified as Gram-negative bacteria, Gram-positive bacteria, acid fast bacilli, fungi, or viruses. Results likely to be associated with environmental or surveillance specimens (e.g., rectal or nasal swabs) were excluded by use of a previously described algorithmic methodology [10], but nasopharyngeal or nasal swabs used for SARS-CoV2 testing and also tested for other respiratory pathogens were included. Admission-onset infections were defined as those occurring within 3 days of admission. Pathogens identified outside this period were considered hospitalonset infections. Antimicrobial utilization was defined as an order for $\geq 24 \mathrm{~h}$ of antibiotic therapy at any point during the admission.

The study dataset was approved as a limited, deidentified dataset for retrospective analysis and was 
exempted from patient consent by the New England Institutional Review Board (Wellesley, Massachusetts) (No. 120180023).

\section{Outcomes}

The primary outcome was the rate of non-SARS-CoV-2 pathogen detection for SARS-COV-2-positive, SARSCoV-2-negative, and SARS-CoV-2-untested patients. Secondary outcomes included rates of specific pathogens, time period of pathogen isolation (admission onset versus hospital onset), antimicrobial usage, and length of stay (LOS) for the three groups.

\section{Statistical analysis}

Statistical analysis involved descriptive data for observed patients, including pathogens, antibiotic therapy, and LOS. Continuous variables were assessed for normality by use of density and quantile-quantile plots. Univariate comparisons between categorical subgroups were performed using chi-square or Fisher's exact tests. Continuous variables were analyzed using Kruskal-Wallis tests and Wilcoxon test for pairwise comparisons. All statistical tests were performed with a pre-specified two-tailed alpha level of 0.05. Analyses were conducted using R ( Ver. 4.0.2, $\mathrm{R}$ Foundation for Statistical Computing, Vienna, Austria) with RStudio (Boston, MA).

\section{Results}

From March 1 to May 31, 2020, 141,621 of 590,960 patients $(24.0 \%)$ were tested for SARS-CoV-2 in 241 medical facilities and 449,339 (76.1\%) were not tested. A total of $17,003(12.0 \%)$ tested patients were positive for SARS-CoV-2 and 124,618 (88.0\%) were negative (Table 1). The proportion of male patients was significantly higher in SARS-CoV-2-positive (53.1\%) vs -negative $(46.5 \%)$ or untested $(44.5 \%)$ patients. Mean (standard deviation [SD]) age was significantly higher in the SARS-CoV-2-positive group (61.7 [18.0] vs 58.5 [20.9] years for SARS-CoV-2-negative and 48.7 [27.3] years for untested patients). Medical facility characteristics and geographic regions by SARS-CoV-2 status are shown in Supplementary Table 1 (see Additional file 1). Of the 241 facilities, $82.6 \%$ were urban hospitals; the bed count was < 100 in $34.9 \%, 100$ to 300 in $39.4 \%$, and $>300$ in $25.7 \%$. The census division with the greatest number of facilities was West South Central (25.3\%) followed by East North Central (17.4\%). At the patient level, the highest SARS-CoV-2-positive rates were in the Northeast $(4392 / 22,364$ tested patients [19.6\%]) and in hospitals that were urban $(16,649 / 131,726[12.6 \%])$, teaching hospitals $(10,405 / 78,250$ [13.3\%]), and with $>300$ beds $(10,475 / 79,922[13.1 \%])$.

Most patients tested for SARS-CoV-2 had specimens collected for microbiologic testing for additional pathogens, although the rate was slightly higher for SARSCoV-2-positive patients (97.8\%) compared with SARSCoV-2-negative patients (91.9\%). Among those not tested for SARS-CoV-2, 41.9\% of patients had specimens collected for microbiologic testing. The proportion of patients with non-SARS-CoV-2 pathogens detected was highest in patients not tested for SARS-CoV-2 (27.9\%) and similar between the SARS-CoV-2-positive (20.9\%) and -negative (21.3\%) groups (Table 1$)$. The presence of multiple non-SARS-CoV-2 pathogens was slightly more common in SARS-CoV-2-negative patients (37.2\% versus $34.3 \%$ for SARS-CoV-2-positive and $34.1 \%$ for untested patients) (Table 1).

\section{Specimen sources and pathogens by SARS-CoV-2 and testing status}

Because patients could have more than one positive specimen and pathogen, the totals for positive specimens were higher than the number of patients with specimens positive for non-SARS-CoV-2 pathogens (Table 2).

Table 1 Baseline characteristics and microbiology testing by SARS-CoV-2 and testing status

\begin{tabular}{|c|c|c|c|}
\hline \multirow[t]{2}{*}{ Characteristic } & \multirow{2}{*}{$\begin{array}{l}\text { Untested for } \\
\text { SARS-CoV-2 } \\
(n=449,339)\end{array}$} & \multicolumn{2}{|l|}{ Tested for SARS-CoV-2 } \\
\hline & & $\begin{array}{l}\text { SARS-CoV-2 negative } \\
(n=124,618)\end{array}$ & $\begin{array}{l}\text { SARS-CoV-2 positive } \\
(n=17,003)\end{array}$ \\
\hline \multicolumn{4}{|l|}{ Demographics } \\
\hline Male sex, n (\%) & $199,732(44.5 \%)$ & $57,924(46.5 \%)$ & $9026(53.1 \%)$ \\
\hline Age, mean (SD) years & $48.7(27.3)$ & $58.5(20.9)$ & $61.7(18.0)$ \\
\hline \multicolumn{4}{|l|}{ Specimens collected for non-SARS-CoV-2 pathogens ${ }^{a} n(\%)$} \\
\hline Yes & $188,057(41.9 \%)$ & $114,550(91.9 \%)$ & $16,637(97.8 \%)$ \\
\hline No & $261,282(58.1 \%)$ & $10,068(8.1 \%)$ & $366(2.1 \%)$ \\
\hline \multicolumn{4}{|l|}{ Specimens positive for non-SARS-CoV-2 pathogens ${ }^{a}$} \\
\hline Any pathogen, $\mathrm{n}$ (\% of patients with specimens collected) & $52,418(27.9 \%)$ & $24,442(21.3 \%)$ & $3473(20.9 \%)$ \\
\hline Multiple pathogens, $\mathrm{n}$ (\% of specimens with any pathogen) & $17,871(34.1 \%)$ & $9101(37.2 \%)$ & 1192 (34.3\%) \\
\hline
\end{tabular}

${ }^{a}$ Defined as any bacteria, fungus, or virus other than SARS-CoV-2 
Table 2 Onset, source, and non-SARS-CoV-2 pathogens ${ }^{a}$ by SARS-CoV-2 and testing status

\begin{tabular}{|c|c|c|c|c|}
\hline \multirow{2}{*}{$\begin{array}{l}\text { Specimen onset, source, and pathogens } \\
\text { n (\% positive specimens) }\end{array}$} & \multirow{2}{*}{$\begin{array}{l}\text { Untested for } \\
\text { SARS-CoV-2 }\end{array}$} & \multicolumn{2}{|l|}{ Tested for SARS-CoV-2 } & \multirow{2}{*}{$\begin{array}{l}P \\
\text { value }\end{array}$} \\
\hline & & SARS-CoV-2 negative & SARS-CoV-2 positive & \\
\hline Any positive non-SARS-CoV-2 specimen ${ }^{b}$ & $73,315(100 \%)$ & $38,753(100 \%)$ & $5012(100 \%)$ & \\
\hline Timing of non-SARS-CoV-2 pathogen detection & & & & $<0.05$ \\
\hline Admission period & $59,016(80.5 \%)$ & $30,141(77.8 \%)$ & $2889(57.6 \%)$ & \\
\hline Hospital-onset period (> 3 days) & $14,299(19.5 \%)$ & $8612(22.2 \%)$ & $2123(42.4 \%)$ & \\
\hline Non-SARS-CoV-2 specimen source & & & & $<0.05$ \\
\hline Urine & $20,807(28.4 \%)$ & $10,077(26.0 \%)$ & 1697 (33.9\%) & \\
\hline Respiratory & $9626(13.1 \%)$ & $5435(14.0 \%)$ & $1228(24.5 \%)$ & \\
\hline Blood & $11,185(15.3 \%)$ & $9530(24.6 \%)$ & $1020(20.4 \%)$ & \\
\hline Other & $16,393(22.4 \%)$ & $7474(19.3 \%)$ & $776(15.5 \%)$ & \\
\hline Skin/Wound & $14,033(19.1 \%)$ & $5698(14.7 \%)$ & $271(5.3 \%)$ & \\
\hline Intra-abdominal & $1271(1.7 \%)$ & $539(1.4 \%)$ & $20(0.4 \%)$ & \\
\hline \multicolumn{5}{|l|}{ Non-SARS-CoV-2 pathogens ${ }^{a}$} \\
\hline Any bacteria & $56,215(76.7 \%)$ & $30,952(79.9 \%)$ & 3972 (79.2\%) & \\
\hline Gram-negative & $31,887(43.5 \%)$ & $17,087(44.1 \%)$ & $2280(45.5 \%)$ & $<0.05$ \\
\hline Enterobacterales & $22,289(30.4 \%)$ & $11,939(30.8 \%)$ & $1594(31.8 \%)$ & 0.06 \\
\hline Pseudomonas aeruginosa & $2729(3.8 \%)$ & $1837(4.7 \%)$ & $324(6.5 \%)$ & $<0.05$ \\
\hline Stenotrophomonas maltophilia & $302(0.4 \%)$ & $238(0.6 \%)$ & $39(0.8 \%)$ & $<0.05$ \\
\hline Acinetobacter baumannii & $145(0.2 \%)$ & $84(0.2 \%)$ & $13(0.3 \%)$ & 0.56 \\
\hline Gram-positive & $24,035(32.8 \%)$ & $13,532(34.9 \%)$ & $1670(33.3 \%)$ & $<0.05$ \\
\hline Staphylococcus aureus & $10,147(13.8 \%)$ & $6120(15.8 \%)$ & $689(13.7 \%)$ & $<0.05$ \\
\hline Enterococcus spp. & $4124(5.6 \%)$ & $2357(6.1 \%)$ & $357(7.1 \%)$ & $<0.05$ \\
\hline Streptococcus pneumoniae & $682(0.9 \%)$ & $513(1.3 \%)$ & $94(1.9 \%)$ & $<0.05$ \\
\hline Non-SARS-CoV-2 virus & $13,150(17.9)$ & $5403(13.9 \%)$ & $543(10.8 \%)$ & $<0.05$ \\
\hline Respiratory viruses & $4398(6.0 \%)$ & $1170(3.0 \%)$ & $111(2.2 \%)$ & $<0.05$ \\
\hline Fungi & $2124(2.9 \%)$ & $1328(3.4 \%)$ & $280(5.6 \%)$ & $<0.05$ \\
\hline Candida spp. & $2990(4.1 \%)$ & $1764(4.6 \%)$ & $410(8.2 \%)$ & $<0.05$ \\
\hline Aspergillus spp. & $104(0.1 \%)$ & $108(0.3 \%)$ & $6(0.1 \%)$ & $<0.05$ \\
\hline
\end{tabular}

${ }^{\mathrm{a}}$ Any bacteria, fungus, or virus other than SARS-CoV-2

${ }^{\mathrm{b}}$ Patients could have more than one positive specimen and pathogen

About three-quarters of positive specimens in the SARSCoV-2-negative and -untested groups were collected during the admission period and therefore likely represented community-acquired coinfections. SARS-CoV-2positive patients had an approximately two-fold higher rate of pathogens detected during the hospital-onset period, which likely represented hospital-acquired infections $(42.4 \%$ vs 22.2 and $19.5 \%$ for SARS-CoV-2-negative and -untested, respectively).

For all three groups, the most frequent source of positive specimens was urine; urinary pathogens were more common in SARS-CoV-2-positive patients (33.9\%) compared with SARS-CoV-2-negative patients $(26.0 \%)$ or untested patients (28.4\%) (Table 2). Respiratory pathogens were identified more frequently in SARS-CoV-2-positive patients (24.5\%) compared with SARS-CoV-2-negative (14.0\%) and -untested (13.1\%) patients. SARS-CoV-2- negative and - untested patients had higher proportions of skin/wound pathogens detected (14.7 and 19.1\%, respectively) compared with SARS-CoV-2-positive patients (5.3\%).

Bacteria accounted for approximately $80 \%$ of pathogens in all three groups (Table 2). Gram-negative bacteria, mostly Enterobacterales, were more common than Gram-positive bacteria, primarily Staphylococcus aureus and Enterococcus spp. The three groups had generally comparable rates of bacterial pathogens, but significantly higher rates of Pseudomonas aeruginosa, Stenotrophomonas maltophilia, Enterococcus spp., and Streptococcus pneumoniae were observed in the SARS-CoV-2-positive group. Rates of non-SARS-CoV-2 respiratory viruses were significantly lower in the SARS-CoV-2-positive group (Table 2). The proportion of patients with specimens positive for Candida spp. was almost twice as high 
in SARS-CoV-2-positive patients (8.2\%) compared with SARS-CoV-2-negative (4.6\%) and -untested (4.1\%) patients.

\section{Antimicrobial usage by SARS-CoV-2 and testing status}

The rate of antimicrobial usage was significantly higher in SARS-CoV-2-positive (68.0\%) versus -negative (45.2\%) and -untested (25.1\%) patients. The mean (SD) time to the first antibiotic order was similar between the two SARS-CoV-2-tested groups (0.9 [2.6] days for SARS-CoV-2- positive and 0.9 [2.3] days for SARS-CoV2-negative) but significantly longer in the untested group (1.4 [5.8] days). Mean (SD) duration of antibiotic treatment was 6.1 (5.2) days for SARS-CoV-2-positive patients compared with 4.8 (4.5) for -negative and 4.1 (3.9) for -untested patients.

The most frequently prescribed antimicrobial class in all three groups was cephalosporins, mostly ceftriaxone (Table 3). An order for a macrolide, primarily azithromycin, was far more common in SARS-CoV-2-positive patients (23.4\%) compared with SARS-CoV-2-negative (9.6\%) and -untested (6.3\%) patients.

\section{Outcomes by SARS-CoV-2 and testing status}

Hospital and ICU LOS were significantly longer for SARS-CoV-2-positive versus SARS-CoV-2-negative and - untested patients (Table 4). A positive pathogen specimen was associated with a longer LOS in all groups. In the SARS-CoV-2-positive group, the mean (SD) length of stay with a positive pathogen specimen was 13.7 [15.7] days vs 8.2 (11.5) days for patients with a negative pathogen specimen. LOS was further increased by the presence of multiple pathogens (17.5 [16.1] days for SARS-CoV-2-positive patients).

\section{Discussion}

Experts have identified an urgent need for accurate information on potential coinfection and superinfection rates in patients with SARS-CoV-2 to help inform diagnosis, disease management, and antimicrobial stewardship during the COVID-19 pandemic [3-6]. In our study, there was a high rate of testing for non-SARS$\mathrm{CoV}-2$ pathogens among those tested for SARS-CoV-2 infection; approximately $20 \%$ of patients tested for SARS-CoV-2 had a positive specimen for an additional pathogen, regardless of SARS-CoV-2 status. However, SARS-CoV-2-positive patients had higher rates of hospital-onset pathogens, greater antimicrobial usage, and extended hospital and ICU LOS compared with SARS-CoV-2-negative or -untested patients.

During our 3-month study (March to May), 12\% of hospitalized adult patients tested for SARS-CoV-2 in US acute care facilities were positive for this virus. As might be expected, testing for additional pathogens was far more common in patients tested for SARS-CoV-2 (more than $90 \%$ ) compared with patients that were not tested

Table 3 Antimicrobial usage by SARS-COV-2 and testing status

\begin{tabular}{|c|c|c|c|}
\hline \multirow{2}{*}{$\begin{array}{l}\text { Antimicrobial } \\
\mathrm{n} \text { (\% of total antimicrobials) }\end{array}$} & \multirow{2}{*}{$\begin{array}{l}\text { Not tested for } \\
\text { SARS-CoV-2 } \\
(n=452,024)\end{array}$} & \multicolumn{2}{|l|}{ Tested for SARS-CoV-2 } \\
\hline & & $\begin{array}{l}\text { SARS-CoV-2 negative } \\
(n=124,927)\end{array}$ & $\begin{array}{l}\text { SARS-CoV-2 positive } \\
(n=17,049)\end{array}$ \\
\hline Total number of antimicrobials ${ }^{a}$ & $225,692(100 \%)$ & $133,735(100 \%)$ & $31,981(100 \%)$ \\
\hline Antibacterial & $211,088(93.5 \%)$ & $125,811(94.1 \%)$ & $29,828(93.3 \%)$ \\
\hline Cephalosporin & $61,468(27.2 \%)$ & $37,514(28.1 \%)$ & $9142(28.6 \%)$ \\
\hline Ceftriaxone & $32,198(14.3 \%)$ & $20,081(15.0 \%)$ & $5864(18.3 \%)$ \\
\hline Cefepime & $13,201(5.8 \%)$ & $10,463(7.8 \%)$ & $2647(8.3 \%)$ \\
\hline Macrolides & $14,200(6.3 \%)$ & $12,883(9.6 \%)$ & 7482 (23.4\%) \\
\hline Azithromycin & $13,632(6.0 \%)$ & $12,642(9.5 \%)$ & 7461 (23.4\%) \\
\hline Glycopeptides & $37,961(16.8 \%)$ & $23,586(17.6 \%)$ & $4254(13.3 \%)$ \\
\hline Vancomycin & $37,955(16.8 \%)$ & $23,585(17.6 \%)$ & $4254(13.3 \%)$ \\
\hline Beta-lactam/beta-lactamase inhibitors & $31,642(14.0 \%)$ & $17,997(13.5 \%)$ & $3065(9.6 \%)$ \\
\hline Piperacillin/tazobactam & $24,729(11.0 \%)$ & $14,145(10.6 \%)$ & $1981(6.2 \%)$ \\
\hline Tetracyclines & $6668(3.0 \%)$ & $5585(4.2 \%)$ & $2038(6.4 \%)$ \\
\hline Carbapenems & $7684(3.4 \%)$ & $5068(3.8 \%)$ & $1145(3.6 \%)$ \\
\hline Fluoroquinolones & $14,171(6.3 \%)$ & $7119(5.3 \%)$ & $800(2.5 \%)$ \\
\hline Antivirals & $8055(3.6 \%)$ & $3918(2.9 \%)$ & $1574(4.9 \%)$ \\
\hline Neuraminidase inhibitors & $2748(1.2 \%)$ & $823(0.6 \%)$ & $950(3.0 \%)$ \\
\hline Antifungals & $6549(2.9 \%)$ & $4006(3.0 \%)$ & $579(1.8 \%)$ \\
\hline
\end{tabular}

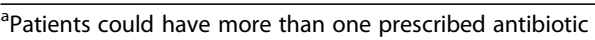


Table 4 Length of stay by SARS-CoV-2, testing, and non-SARS-CoV-2 pathogen status

\begin{tabular}{|c|c|c|c|c|c|c|}
\hline \multirow[t]{3}{*}{ Admission site and pathogen status } & \multirow{2}{*}{\multicolumn{2}{|c|}{ Not tested for SARS-CoV-2 }} & \multicolumn{4}{|c|}{ Tested for SARS-CoV-2 } \\
\hline & & & \multicolumn{2}{|c|}{ SARS-CoV-2 negative } & \multicolumn{2}{|c|}{ SARS-CoV-2 positive } \\
\hline & $\mathbf{n}$ & LOS & $\mathbf{n}$ & LOS & $\mathbf{n}$ & LOS \\
\hline Hospital $^{a}$ & 449,339 & $4.2(8.0)[2]$ & 124,618 & $5.1(8.9)[3]$ & 17,003 & $8.6(11.4)[6]$ \\
\hline Positive for non-SARS-CoV-2 pathogen & 52,418 & $7.1(11.0)[4]$ & 24,442 & $8.2(11.5)[5]$ & 3483 & $13.7(15.7)[9]$ \\
\hline Negative for non-SARS-CoV-2 pathogen & 396,921 & $3.9(7.4)[2]$ & 100,176 & $4.3(7.9)[3]$ & 13,566 & $7.3(9.6)[5]$ \\
\hline Multiple non-SARS-CoV-2 pathogens & 17,871 & $8.7(13.2)[5]$ & 9101 & $10.2(14.6)[6]$ & 1192 & $17.5(16.1)[14$ \\
\hline$I C U^{a}$ & 47,629 & $3.6(5.9)[2]$ & 21,060 & $3.8(6.2)[2]$ & 4076 & $7.8(8.5)[5]$ \\
\hline
\end{tabular}

Data are expressed as mean (standard deviation) [median] days. $P<0.05$ across groups for all outcomes

Note: ICU intensive care unit, LOS length of stay

${ }^{a}$ Overall hospital and ICU LOS include patients with no specimen collected

for SARS-CoV-2 (42\%), as many untested patients were likely admitted for noninfectious causes with no reason to expect or test for a clinically relevant pathogen. Nevertheless, the rate of pathogen detection was slightly higher among untested patients (28\% versus $21 \%)$. Urine was the most frequent specimen source for pathogens in all groups, followed by respiratory samples for SARS-CoV-2-positive patients. The relatively low yield of non-SARS-CoV-2 pathogens across all subgroups may be relevant to hospitals coping with the redeployment of diagnostics to focus on the COVID-19 pandemic $[4,11]$.

In presenting these data, it is important to note that we do not consider the SARS-CoV-2-negative or - untested subgroups to be "controls" for the SARS-CoV-2positive patients in this study, as the subgroups differed in many important characteristics including the proportion of patients with hospital-onset pathogens. Rather, we believe the inclusion of these other subgroups provides context for the findings in the SARS-CoV-2 tested subgroup.

Other studies have come to varying conclusions concerning rates of coinfection in patients with SARS-CoV2 [11-15]. The differences among studies may relate to study location and to testing procedures. The strength of our study is use of a broader approach on two levels: 1) we assessed all specimens collected during the admission, rather than focusing solely on respiratory pathogens; and 2) we included regionally diverse hospitals throughout the US. Given the extensive geographic variations in SARS-CoV-2 infection rates during the course of the pandemic $[16,17]$ and region-specific patient characteristics [18], national data may provide a more complete view of SARS-CoV-2 infections and attendant coinfections.

Rates of specific pathogens were generally comparable among the three groups, although rates of some bacteria, including $P$. aeruginosa, and rates of Candida spp. were significantly higher in SARS-CoV-2-positive patients compared with -negative or - untested patients. Both pathogens are frequently found in the respiratory tract of ventilated patients or critically ill patients, and both are associated with previous antibiotic treatment [19]. In contrast, rates of Aspergillus were highest in SARS-CoV-2-negative patients. Variability in methods used to detect Aspergillus impact reported rates of infection [20]. Studies using various methods have reported pulmonary aspergillosis rates of 20 to $30 \%$ in the most severely ill, mechanically ventilated COVID-19 patients [20], but the overall rate is much lower. In line with the numbers reported here, a recent study identified COVID-19-associated pulmonary aspergillosis in $0.3 \%$ of all hospitalized COVID-19 patients [21].

In SARS-CoV-2-positive patients, $58 \%$ of non-SARSCoV-2 pathogens were identified in specimens collected within 3 days of admission. The delayed onset of the remaining $42 \%$ of positive pathogen detections indicates the increased risk of healthcare exposure for the acquisition of opportunistic pathogens and/or healthcareassociated infections. In contrast, positive pathogen detection in specimens collected within 3 days of admission occurred at higher rates in SARS-CoV-2-negative (78\%) and -untested (81\%) patients, and rates of subsequent hospital-onset positive pathogen detections were correspondingly reduced. The different temporal distribution of positive specimens among these three groups suggests that characteristics associated with hospitalized COVID-19 patients [3], including comorbidities, the severity of illness associated with SARS-CoV-2, extended hospital lengths of stay, and the frequent need for ventilation $[15,22]$, perhaps in conjunction with immunomodulatory treatments, may increase susceptibility to infection with other pathogens [3]. In addition, prolonged SARS-CoV-2 infection could itself potentially confer an immunosuppressed state that increases 
vulnerability to opportunistic infections [23]. Rates of healthcare-associated infections may have also been impacted by the heavy burden on hospitals during COVID19 surges, leading US medical professional societies to urge the Department of Health and Human Services to suspend reimbursement penalties for healthcareassociated infections during the pandemic [24]. Given the fact that urine and respiratory sources predominated as sources of pathogens in SARS-CoV-2-positive patients, it is feasible that infection prevention bundles and the use of personal protective equipment may have been adversely affected as a result of the pandemic $[25,26]$.

Histopathologic studies support an important role for S. pneumoniae and other Gram-positive pathogens, including Streptococcus pyogenes and S. aureus, in contributing to lung damage and causing bacterial pneumonia in patients with influenza [27]. Gram-negative pathogens have been identified as the major cause of bacterial pneumonia in critically ill patients with COVID-19 [28]. In addition to lung damage, pathogens can influence a number of other pathologic processes. For instance, during the influenza A H1N1 pandemic in 2009, coinfection with $S$. aureus was reported to be associated with an increased risk of severe coagulopathy in children [29]. It should be noted, however, that the correlation between copathogens and other severe clinical outcomes is not necessarily causative; the presence of copathogens might instead act as a marker for more severe chronic conditions or reflect differences in individual immune responses.

In our study, SARS-CoV-2-positive patients had longer hospital and ICU LOS compared with SARS-CoV-2negative or - untested patients. Identification of a pathogen was associated with increased LOS in all groups, but was particularly notable in SARS-CoV-2-positive patients, who had a mean hospital LOS of almost 14 days in the SARS-CoV-2-positive/pathogen specimen-positive group compared with 7 days in the SARS-CoV-2-positive/pathogen specimen-negative group. The presence of multiple pathogens further increased LOS. These data are derived from patients with additional pathogens identified during both the admission onset and hospital onset periods.

Antimicrobial usage was significantly higher in SARSCoV-2-positive patients (68\% vs $45 \%$ for SARS-CoV-2negative and $25 \%$ for -untested patients), despite similar or lower rates of pathogen-positive specimens. The higher rate of antimicrobial use may be due to initiation of empiric therapy for suspected pneumonia or sepsis, consistent with guidelines for the latter [30]. Other studies have also observed higher utilization of antibiotics in patients with SARS-CoV-2 with no identified coinfection $[4,31,32]$. Although most drug classes were used at comparable levels in the different groups, the use of macrolides was much higher in SARS-CoV-2-positive patients. This may be due to the widely reported increase in radiographic opacities in COVID-19 patients concurrent with signs and symptoms of pneumonia at presentation [33]. Macrolide use was also likely influenced by early reports concerning the potential efficacy of hydroxychloroquine plus azithromycin in managing COVID-19 [34], which were not supported by subsequent studies $[35,36]$.

The treatment patterns observed in our study likely reflect difficulties in making treatment decisions in critically ill patients, prolonged turnaround time for SARSCoV-2 testing, particularly in the early days of the pandemic [37], and concerns over potential bacterial superinfection in SARS-CoV-2, but may also indicate overuse of antimicrobials. Collateral damage from antimicrobial overuse includes increased selection of antimicrobial resistance and opportunistic pathogens such as C. difficile, adverse effects of drugs, and unnecessary treatment costs $[3,4,9,38]$. Continued monitoring of the utilization and appropriateness of antimicrobial use among SARS-CoV2 patients is required to identify antimicrobial stewardship opportunities.

As with any database study, the study reported here has important limitations. SARS-CoV-2 and pathogen status were based on reports from institutional facilities; there was no uniform method of testing or central laboratory. The sensitivity and specificity of SARS-CoV-2 PCR assays are known to vary based on several factors, including time from exposure [39, 40]. No case definition for COVID-19 disease was applied, consistent with current medical care practices, and we did not assess disease severity, so it is possible that some of the SARSCoV-2 patients identified here were asymptomatic and admitted for other causes. Although our established algorithm [10] is designed to remove admissions with colonizing microbes from the analyses, some of the pathogens resulting in positive specimens may not have been associated with clinically significant infections. Certain geographic areas may have been underrepresented by our database, although the northeast, which had high SARS-CoV-2 rates in the earliest phase, is well represented. Influenza is not common during the months included in this study, so our findings concerning co-infection with respiratory viruses may not be representative of other times of the year. Our study reflects an early period in the COVID-19 pandemic; it will be important to follow changes in these patterns over time to assess changes in virus epidemiology and in healthcare resource utilization.

The findings reported in our study raise several important points of clinical relevance. First, potential copathogens (concurrent infections or superinfections) occur in approximately $21 \%$ of SARS-CoV-2 patients, so 
the identification of another pathogen does not rule out the presence of SARS-CoV-2. Second, although overall potential copathogen rates were similar regardless of SARS-CoV-2 status, clinicians should be aware of the increased risk of secondary infections in patients with SARS-CoV-2 and the burden associated with copathogens. The presence of an additional pathogen was associated with a marked increase in hospital and ICU LOS for all groups, but the difference was greatest in SARSCoV-2-positive patients. Third, about $80 \%$ of SARSCoV-2-positive patients do not have a detectable copathogen, so antimicrobial therapy should be evaluated daily and de-escalated when possible. Our data underscore the need for sensitive and specific diagnostics to help inform appropriate antimicrobial stewardship. The deployment of early respiratory diagnostic tests relative to the first administration of an antimicrobial is therefore a prime consideration, especially for septic patients who will likely receive an antimicrobial within the first hour of acute care.

During the 3-month period encompassed by this study, SARS-CoV-2-positive patients had specimens collected more than twice as often as patients not tested for SARS-CoV-2. Additionally, SARS-CoV-2-positive patients were 1.5 -fold more likely to be prescribed antibiotics than SARS-CoV-2-negative patients, and 2.7-fold more likely than untested patients. Our findings document epidemiological variations in specimen collection, pathogen prevalence, and antimicrobial utilization associated with SARS-CoV-2 status that may be useful in helping clinicians assess and manage patients with suspected or confirmed COVID-19, and highlight the considerable operational burden that COVID-19 imposes on healthcare systems nationwide.

\section{Supplementary Information}

The online version contains supplementary material available at https://doi. org/10.1186/s12879-021-05877-3.

Additional file 1: Supplementary Table 1. Patients by Medical Facility Characteristics and Geographic Location.

\section{Acknowledgments}

We thank Sharon L. Cross, PhD, Fusion MD Medical Science Network, Inc., Montreal, Canada, for providing manuscript support with funding from Becton, Dickinson \& Company.

\section{Authors' contributions}

$L P, L F, K C Y, K A B, P M, C D A$, and VG were involved in study design and in data analysis and interpretation. $L P, L F, K C Y$, and VG drafted the manuscript. LV and AS provided analytic and statistical support. All the authors have read and approved the final manuscript.

\section{Funding}

This work was supported by a grant from Merck Sharp \& Dohme Corp., a subsidiary of Merck \& Co., Inc., Kenilworth, NJ, USA to Becton, Dickinson, and Company, Franklin Lakes, NJ, US. Medical writing was supported by Becton, Dickinson \& Company.

\section{Availability of data and materials}

The datasets used and/or analysed during the current study are available from the corresponding author on reasonable request.

\section{Ethics approval and consent to participate}

The study was performed in accordance with all relevant guidelines and regulations, including the Declaration of Helsinki. Outcome studies using this retrospective, deidentified dataset were approved and informed consent was waived by the New England Institutional Review Board (Wellesley,

Massachusetts; No. 120180023).

\section{Consent for publication}

Not applicable

\section{Competing interests}

LP, LF, KAB, PM, and CDA are employees of Merck Sharp \& Dohme Corp., a subsidiary of Merck \& Co., Inc., Kenilworth, NJ, USA and shareholders in Merck \& Co., Inc., Kenilworth, NJ, USA. KCY, LV, AS, and VG are employees of Becton, Dickinson \& Company, which was contracted by Merck to conduct the study. KCY and VG also own stock in Becton, Dickinson \& Company.

\section{Author details}

${ }^{1}$ Merck \& Co., Inc., Kenilworth, NJ, USA. ${ }^{2}$ Becton, Dickinson and Company, Franklin Lakes, NJ, USA.

Received: 3 December 2020 Accepted: 3 February 2021

Published online: 27 February 2021

\section{References}

1. Esper FP, Spahlinger T, Zhou L. Rate and influence of respiratory virus coinfection on pandemic (H1N1) influenza disease. J Inf Secur. 2011;63:260-6.

2. Maclntyre CR, Chughtai AA, Barnes M, Ridda I, Seale H, Toms R, et al. The role of pneumonia and secondary bacterial infection in fatal and serious outcomes of pandemic influenza a(H1N1)pdm09. BMC Infect Dis. 2018;18: 637.

3. Clancy CJ, Nguyen MH. Coronavirus disease 2019, superinfections, and antimicrobial development: what can we expect? Clin Infect Dis. 2020; [online ahead of print].

4. Rawson TM, Moore LSP, Zhu N, Ranganathan N, Skolimowska K, Gilchrist M, et al. Bacterial and fungal co-infection in individuals with coronavirus: a rapid review to support COVID-19 antimicrobial prescribing. Clin Infect Dis. 2020;71:2459-68.

5. COVID-19 Treatment Guidelines Panel. Coronavirus disease 2019 (COVID-19) treatment guidelines. National Institutes of Health. https://www.covid19trea tmentguidelines.nih.gov/.

6. Rawson TM, Ming D, Ahmad R, Moore LSP, Holmes AH. Antimicrobial use, drug-resistant infections, and COVID-19. Nat Rev Microbiol. 2020;18:409-10.

7. McCann E, Srinivasan A, DeRyke CA, Ye G, DePestel DD, Murray J, et al. Carbapenem non-susceptible Gram-negative pathogens in ICU and non-ICU Settings in US hospitals in 2017: A multicenter study. Open Forum Infect Dis. 2018;5:ofy241.

8. Gupta V, Ye G, Olesky M, Lawrence K, Murray J, Yu K. National prevalence estimates for resistant Enterobacteriaceae and Acinetobacter species in hospitalized patients in the United States. Int J Infect Dis. 2019;85:203-11.

9. Tabak YP, Srinivasan A, Yu K, et al. Hospital-level high-risk antibiotic use in relation to hospital-associated Clostridioides difficile infections: retrospective analysis of 2016-2017 data from US hospitals. Infect Control Hosp Epidemiol. 2019:40:1229-35.

10. Brossette SE, Hacek DM, Gavin PJ, Kamdar MA, Gadbois KD, Fisher AG, et al. A laboratory-based, hospital-wide, electronic marker for nosocomial infection: the future of infection control surveillance? Am J Clin Pathol. 2006:125:34-9.

11. Sepulveda J, Westblade LF, Whittier S, Satlin MJ, Greendyke WG, Aaron JG, et al. Bacteremia and blood culture utilization during COVID-19 surge in New York City. J Clin Microbiol. 2020;58:e00875-20.

12. Hazra A, Collison M, Pisano J, Kumar M, Oehler C, Ridgway JP. Coinfections with SARS-CoV-2 and other respiratory pathogens. Infect Control Hosp Epidemiol. 2020;41:1228-9.

13. Hughes S, Troise O, Donaldson H, Mughal N, Moore LS. Bacterial and fungal coinfection among hospitalized patients with COVID-19: a retrospective 
cohort study in a UK secondary care setting. Clin Microbiol Infect. 2020;26: 1395-99.

14. Kim D, Quinn J, Pinsky B, Shah NH, Brown I. Rates of co-infection between SARS-CoV-2 and other respiratory pathogens. JAMA. 2020;323:2085-86.

15. Richardson S, Hirsch JS, Narasimhan M, Crawford JM, McGinn T, Davidson $\mathrm{KW}$, et al. Presenting characteristics, comorbidities, and outcomes among 5700 patients hospitalized with COVID-19 in the New York City area. JAMA. 2020;323:2052-9.

16. CDC COVID-19 Response Team. Geographic differences in COVID-19 cases, deaths, and incidence - United States, February 12-April 7, 2020. MMWR Morb Mortal Wkly Rep. 2020;69:465-71.

17. Wang Y, Liu Y, Struthers J, Lian M. Spatiotemporal characteristics of COVID19 epidemic in the United States. Clin Infect Dis. 2020; [online ahead of print].

18. Myers CA, Slack T, Broyles ST, Heymsfield SB, Church TS, Martin CK. Diabetes prevalence is associated with different community factors in the diabetes belt versus the rest of the United States. Obesity. 2017;25:452-9.

19. Ader F. Interaction between Pseudomonas aeruginosa and Candida albicans in the respiratory tract of critically ill patients. Curr Respir Med Rev. 2010;6:15-8.

20. Marr KA, Platt A, Tornheim JA, Zhang SX, Datta K, Cardozo C, et al. Aspergillosis complicating severe coronavirus disease. Emerg Infect Dis. 2021;27:18-25

21. Machado M, Valerio M, Álvarez-Uría A, Olmedo M, Veintimilla C, Padilla B, et al. Invasive pulmonary aspergillosis in the COVID-19 era: an expected new entity. Mycoses. 2020;64:132-43.

22. Zhou F, Yu T, Du R, Fan G, Liu Y, Liu Z, et al. Clinical course and risk factors for mortality of adult inpatients with COVID-19 in Wuhan, China: a retrospective cohort study. Lancet. 2020;395:1054-62.

23. Diao B, Wang C, Tan Y, Chen X, Liu Y, Ning L, et al. Reduction and functional exhaustion of T cells in patient with coronavirus diseases 2019 (COVID-19). Front Immunol. 2020;11:827.

24. Dall C. Med societies ask that healthcare infection penalties be suspended. Center for Infectious Disease Research and Policy. https://www.cidrap.umn. edu/news-perspective/2021/01/med-societies-ask-healthcare-infection-pena Ities-be-suspended.

25. Adams JG, Walls RM. Supporting the health care workforce during the COVID-19 global epidemic. JAMA. 2020;323:1439-40.

26. Reddy SC, Valderrama AL, Kuhar DT. Improving the use of personal protective equipment: applying lessons learned. Clin Infect Dis. 2019; 69(Suppl 3):S165-70.

27. Centers for Disease Control and Prevention (CDC). Bacterial coinfections in lung tissue specimens from fatal cases of 2009 pandemic influenza A (H1N1) - United States, May-August 2009. MMWR Morb Mortal Wkly Rep. 2009:58:1071-4.

28. Dudoignon E, Caméléna F, Deniau B, Habay A, Coutrot M, Ressaire Q, et al. Bacterial pneumonia in COVID-19 critically ill patients: a case series. Clin Infect Dis. 2020; [online ahead of print].

29. Nguyen T, Kyle UG, Jaimon N, Tcharmtchi MH, Coss-Bu JA, Lam F, et al. Coinfection with staphylococcus aureus increases risk of severe coagulopathy in critically ill children with influenza A (H1N1) virus infection. Crit Care Med. 2012;40:3246-50

30. Rhodes A, Evans LE, Alhazzani W, Levy MM, Antonelli M, Ferrer R, et al. Surviving sepsis campaign: international guidelines for management of sepsis and septic shock: 2016. Crit Care Med. 2017;45:486-552.

31. Nori P, Cowman K, Chen V, Bartash R, Szymczak W, Madaline T, et al. Bacterial and fungal co-infections in COVID-19 patients hospitalized during the New York City pandemic surge. Infect Control Hosp Epidemiol. 2021;42:84-8.

32. Vaughn VM, Gandhi T, Petty LA, Patel PK, Prescott HC, Malani AN, et al. Empiric antibacterial therapy and community-onset bacterial co-infection in patients hospitalized with COVID-19: a multi-hospital cohort study. Clin Infect Dis. 2020; [online ahead of print].

33. Wong HYF, Lam HYS, Fong AH, Leung ST, Chin TWY, Lo CSY, et al. Frequency and distribution of chest radiographic findings in patients positive for COVID-19. Radiology. 2020;296:E72-8.

34. Gautret P, Lagier JC, Parola P, Hoang VT, Meddeb L, Mailhe M, et al. Hydroxychloroquine and azithromycin as a treatment of COVID-19: results of an open-label non-randomized clinical trial. Int J Antimicrob Agents. 2020;56:105949.

35. Geleris J, Sun Y, Platt J, Zucker J, Baldwin M, Hripcsak G, et al. Observational study of hydroxychloroquine in hospitalized patients with Covid-19. N Engl J Med. 2020;382:2411-8.
36. Mercuro NJ, Yen CF, Shim DJ, Maher TR, McCoy CM, Zimetbaum PJ, et al. Risk of QT interval prolongation associated with use of hydroxychloroquine with or without concomitant azithromycin among hospitalized patients testing positive for coronavirus disease 2019 (COVID-19). JAMA Cardiol. 2020;5:1036-41.

37. Ward S, Lindsley A, Courter J, Assa'ad A. Clinical testing for COVID-19. J Allergy Clin Immunol. 2020;146:23-34.

38. Bauer KA, Kullar R, Gilchrist M, File TM Jr. Antibiotics and adverse events: the role of antimicrobial stewardship programs in 'doing no harm'. Curr Opin Infect Dis. 2019;32:553-8.

39. Kucirka LM, Lauer SA, Laeyendecker O, Boon D, Lessler J. Variation in falsenegative rate of reverse transcriptase polymerase chain reaction-based SARS-CoV-2 tests by time since exposure. Ann Intern Med. 2020;173:262-7.

40. Green DA, Zucker J, Westblade LF, Whittier S, Rennert H, Velu P, et al. Clinical performance of SARS-CoV-2 molecular testing. J Clin Microbiol. 2020;58:e0995-20

\section{Publisher's Note}

Springer Nature remains neutral with regard to jurisdictional claims in published maps and institutional affiliations.

\section{Ready to submit your research? Choose BMC and benefit from:}

- fast, convenient online submission

- thorough peer review by experienced researchers in your field

- rapid publication on acceptance

- support for research data, including large and complex data types

- gold Open Access which fosters wider collaboration and increased citations

- maximum visibility for your research: over $100 \mathrm{M}$ website views per year

At BMC, research is always in progress.

Learn more biomedcentral.com/submissions 